\title{
Authorship and Authenticity in the Transmedia Brand: The Case of Marvel's Agents of S.H.I.E.L.D.
}

\author{
LEORA HADAS, University of Nottingham
}

\begin{abstract}
The Marvel Cinematic Universe (MCU) is the first filmmaking endeavour of its kind: multiple separate superhero films taking place within a single diegetic world, united in a single sequel, The Avengers (2012). The third highest-grossing film in history, The Avengers drew not only on the success of its prequels, its established characters and its stars, but perhaps most of all on its writerdirector, cult favourite television auteur Joss Whedon. Having delivered on the film, and with considerable experience in creating quirky, character-based telefantasy, Whedon was a natural choice for Marvel for creating the MCU's first expansion into television, ABC's Marvel's Agents of S.H.I.E.LD (ABC Studios/Marvel Television/Mutant Enemy, 2013- ).
\end{abstract}

This article examines the use of Whedon's name and his presence in the promotional discourse of Agents of S.H.I.E.LD as a case study of the role of the media creator in extending the transmedia brand. With the names of creators becoming increasingly visible in association with many texts where they were previously absent, such as television series and blockbuster Hollywood cinema, the use of the author name as a brand name sees growing prevalence across the screen industries. In theorizing transmedia storytelling, Elizabeth Evans (2010) has, accordingly, named authorship as one of the key dimensions in which cohesion is established. In this context, I examine the use of Whedon's involvement in the Marvel Cinematic Universe, where the discourse of authorship operates as a guarantor of consistency and authenticity. Looking at the promotional surround of the series in the form of trailers, interviews and convention panels, I track the writer-director's function in validating the brand extension, acting as the glue that holds the transmedia universe together. I examine Whedon's place within the matrix of the franchise, as his authorship is incorporated into and potentially competes with Marvel Studios' own brand.

\section{KEYWORDS}

Transmedia, branding, Joss Whedon, Marvel Studios, television authorship.

\section{Background: Transmedia Branding and the Authenticity Problem}

In a media landscape characterized, more than ever, by uncertainty, fragmentation and high risks, the search is always on for new forms of storytelling. The media industries are continuously concerned with finding new ways to engage consumers with products, to secure lasting loyalty and to deploy ideas that have proven successful across content streams. Media branding has emerged as 
an answer to these problems of a crowded marketplace, where attention is difficult to keep and audiences often have more choice than they know what to do with. Branding involves 'the creation and development of a specific identity for a company, product, commodity, group or person' (Levine 2003, 3). A brand is in effect a face (logo and design aesthetics) and personality (associations, values, meanings, related experiences) by which goods or services become distinct and recognizable, and by which a number of not necessarily similar goods or services may be linked together (Lury 2004). As Burghardt Tenderich of the USC Annenberg Innovation Lab says, 'Media and entertainment brands are the story' (Tenderich 2013, 9). The brand identity is derived from the storyworld: its characters, its rules, its aesthetics, its geography, its genre trappings and style all play their part in invoking familiarity in the consumer, and all of these must adhere to a degree of consistency. This is not merely a diegetic consistency, but also a stylistic and thematic one. Indeed, legal battles have been waged over fans' usage of media brands in ways that creators consider to be incompatible with brand values.

Transmedia brands build upon these same principles. A key quality of transmedia according to Henry Jenkins is the consistency of the storyworld, with transmedia storytelling described as 'a process in which integral elements of a fiction get dispersed systematically across multiple delivery channels for the purpose of creating a unified and coordinated entertainment experience. Ideally, each medium makes its own unique contribution to the unfolding of the story' (2007). The transmedia story is, in a sense, a kind of brand; these storyworlds will sometimes even have a logo, the case study in this article being a prime example. There are many advantages to transmedia branding. Spreading a world across media, channels and screens creates an immersive experience that draws audiences in and invites their close involvement. A single identity generates immediate recognisability and immediate distinction in an environment full of alternatives, as fans follow the brand between platforms and thus remain within the system of the media conglomerate. Indeed, as the distribution bottleneck has given way to a content bottleneck in the media industries (Todreas 1999), transmedia brands have become a primary means by which media conglomerates are able to fill a multitude of screens with content.

There are however some problems with this strategy, rooted in this very usefulness in filling many channels and media with a consistently familiar universe. As a marketing logic, branding connotes repetition and tired familiarity, as well as the marketing of a carefully constructed image, both of which are the opposite of creativity. As a transmedia brand expands, each new extension is judged by the audience: is it an authentic creation, a story that needs telling, driven by an absence in the narrative or by genuine artistic expression? Or is it merely a cynical scheme for milking more money from consumers through their devotion to a beloved storyworld? From an industrial perspective, of course, this is a meaningless dichotomy. Few products of the media industries are ever created solely for the sake of either money or art. Yet in popular discourse the division endures, and when a brand extension is deemed to be no more than attaching a logo and trappings to a story without its own merits, the audience backlash can be powerful. Branding as a marketing logic allows media producers to exploit intellectual property (IP) across media, but outside of a marketing discourse, exploitation is not a positive term.

This article examines how this problem of authenticity in transmedia brand extensions can be mitigated by the use of authorship discourses in promotion. It does so by examining a particular transmedia brand taking its first step toward expanding into a new medium, in the form of the television series Marvel's Agents of S.H.I.E.L.D. (ABC Studios/Marvel Television/Mutant Enemy, 
2013- ). Launched September $24^{\text {th }}$ on the ABC network, the series represents the first foray of Marvel Studios and the Marvel Cinematic Universe (henceforth MCU) in live action television. The MCU is already an innovative experiment in a new form of storytelling, Marvel's successful attempt to carry over the concept of the shared universe from comics to film. Its seven films (the Iron Man trilogy (2008, 2010, 2013), The Incredible Hulk (2008), Captain America (2011), Thor (2011) and the crossover film The Avengers (2012)) all take place within the same fictional world, with The Avengers bringing together as a team the heroes that have previously starred in their respective solo films. Produced by Marvel Television, ABC Studios and Mutant Enemy, the television series takes place in the same fictional universe as the films and chronologically follows The Avengers. It runs parallel to the films of the MCU's "Phase 2": Thor: The Dark World (2013), Captain America: The Winter Soldier (2014), Guardians of the Galaxy (to be released August 2014) and Avengers 2: Age of Ultron (to be released 2015).

The relationship between the two media has been the subject of some questions and concerns, due particularly to the fact that Agents of S.H.I.E.L.D. does not feature any of the MCU's signature heroes such as Iron Man and Captain America. Critics have also noted that it will not be able to offer visual and action thrills nearly on the same scale as the films. Its characters were not drawn from the nearly inexhaustible Marvel Comics bank, and its premise made no particular attempt to pick up on any of the plots in the various films. It thus lacks almost any element that would connect it organically to the MCU storyworld-brand or indeed even to the greater Marvel multiverse. On first glance, the show is a fairly standard telefantasy procedural, dealing with a team of experts solving cases and fighting evil, whose only connection to MCU is the logo and the presence of vaguely defined espionage and peacekeeping agency S.H.I.E.L.D. What made this show different? What connected it to the wider transmedia universe? How did it reflect the qualities of the MCU brand, and how was it justified as a valid, true MCU story?

\section{'A Unified Vision': Establishing Authorship}

Of the number of ways in which Marvel's Agents of S.H.I.E.L.D. is identified as a legitimate extension rather than brand exploitation, I will analyse one key strategy: the presence of The Avengers writer-producer Joss Whedon within the show's creative team, and the use of his name and brand in its promotion. Jenkins's (2006) seminal work on transmedia as demonstrated by The Matrix universe already highlighted authorship as one of the key factors that sets transmedia storytelling apart from older concepts, such as spin-off, adaptation and franchising. Jenkins describes the Wackowskis' strategy in crafting their transmedia universe as collaborative authorship, in which other established media creators were tapped to create comics, animation shorts and other texts within the world of the Matrix, tying into the film. These creators, famous figures such as comics writer and novelist Neil Gaiman and animator Shinichiro Watanabe, were invited to incorporate their signature styles into the franchise. This strategy stands in contrast to the more standard procedure of hiring 'hack collaborators who could crank out the games, comics and cartoons' (ibid., 108), a kind of leasing out of IP which Jenkins views as resulting in inferior secondary products. At the same time, the Wackowskis did not leave the production of other Matrix texts to their collaborators, but themselves took part in writing for the Enter the Matrix (2003) game and the comics and contributed to the plotting of several of the Animatrix (2003) shorts. Their presence "made these other Matrix texts a central part of the "canon"' (ibid., 111), establishing them on equal footing with the films as part of the same creative vision. Jenkins thus discussed the potential link of authorship to authenticity in transmedia branding, although the discussion is focused more on issues of consistency. An additional perspective on transmedia authorship is offered by Elizabeth Evans, who proposes the concept of institutional or studio authorship, in which 
'branding and industrial policy combine to create an authorial figure that provides both a marketable coherence and an integrated production process' $(2011,33)$. This concept is in fact excellently demonstrated in Marvel's branding efforts, wherein the company's name, and often its bright red and yellow logo, regularly precede titles even when the result is a bit of a mouthful (note my case in point).

However, to focus on this institutional object is to paint an incomplete picture, ignoring the many ways in which Joss Whedon's name as an individual author is established as a main focal point across the promotional campaign of the new series. This focus begins with ABC's and Marvel's initial announcements of the series (Itzkoff 2012a), continuing in a spot on the cover of Entertainment Weekly (Dove 2013), the description of the series on the ABC website (ABC 2013), and its first trailer (Marvel Entertainment, 2013a). It suggests that branding Agents of S.H.I.E.L.D. with the Marvel name was inadequate for establishing its identity. Merely being marketed as Marvel's apparently proved not to be sufficient glue to hold the transmedia universe together, nor to provide distinction enough to enable the show to stand out among its fellow action procedurals. In order to properly employ the transmedia connection in promoting this new extension, an additional tactic was employed: a foregrounding of the individual creator, the writer-director of The Avengers, who had already left his mark in another medium within that transmedia world.

The first thing to take note of regarding authorship discourses in the promotion of Marvel's Agents of S.H.I.E.L.D. is that the series was conceived from the beginning as authored. Indeed, expanding the Marvel Cinematic Universe into live-action television only became an option after Joss Whedon had not only agreed to write and direct the inevitable Avengers sequel, but had also signed an exclusive long-term deal with Marvel Studios. In addition to his work on Avengers 2, Whedon's role called for him to work on all other upcoming MCU films, doing rewrites and touch-ups to their scripts (Polo 2013). In this capacity, Whedon acts as the unifying thread that runs through the transmedia universe. He is charged with establishing a consistent tone and style that ties other products - the upcoming films and now the televised brand extension - back to the tremendous success of the 'tent-pole' The Avengers: 'One universe, one voice', as MTV's Josh Wigler puts it:

Not to say that Whedon is the sole creative force operating inside the Marvel Cinematic Universe [...] but having Whedon on board as a Marvel Studios creative contributor certainly helps cement a unified vision for this crazy-ambitious universe. If 'Avengers' is an indicator, then this is the exact man we want and need driving the Marvel movies forward [...]. (Wigler, 2012)

Though the MCU films all demonstrably take place in the same world and there are already many diegetic connections between them, it is a singular creator's "vision" that takes centre stage here. Establishing a unified authorship plays its part in using the storyworld as a brand in creating or at least advertising stylistic and thematic consistency that lays over and bridges absences such as shared characters or even storylines. Moving to unify the authorship of their transmedia franchise is a new strategy for Marvel Studios: previous transmedia extensions such as comics taking place within the MCU storyworld did not, until now, involve any of the many screenwriters of the films. Instead they were written by high profile comics writers such as Joe Casey and Peter David, a strategy more reminiscent of the Wackowskis' employment of established creators within the Matrix universe. Yet another creative team worked on the 'Marvel One-Shots' series of short films featured on MCU Blu-ray releases, such as The Consultant (2011) and Item 47 (2012). These previous extensions, in addition to addressing a much smaller and more focused audience, were 
connected directly to the narratives of the MCU films, filling gaps or continuing storylines. Their perfect fit within the universe was not in question, nor the purpose they played in supporting and extending stories in which fans were already invested. Yet television was a different game, representing an unprecedented feat of transmedia expansion in which the story of the same universe would continue to serially unfold across two media. For the first time, the MCU needed its own storyteller.

Joss Whedon is not the only one who could have claimed this position of brand author for the MCU. Marvel Studios president Kevin Feige has played the role of the franchise's central authority in film. He has been named the visionary architect behind the idea of creating a cinematic universe along the logic of the comics universe, with different films all taking place within the same diegetic world. Feige had acted as the face of the MCU brand, and he was singled out by Marvel Comics' president Joe Quesada as being responsible for maintaining continuity between the films and previous transmedia extensions. His role as a central voice establishing the unity and consistency of the MCU across its cinematic texts is clearly significant. However, Feige's actual involvement with Agents of S.H.I.E.L.D. has been minimal due to Marvel's industrial structure, which places the series outside his jurisdiction and under that of Marvel's Head of Television. Yet as I shall soon discuss, the promotional use of authorship discourses needn't have much to do with the reality of a project. The fact that Marvel elected to leave Feige out of promoting the series is noteworthy. Meanwhile, their Head of Television, Jeph Loeb, also possesses extensive film, television and comics experience, yet he remains a secondary figure within the series' creative team, utterly overshadowed by Whedon's presence in everything from interviews to trailers and adverts.

What then makes Whedon the best name with which to sell Marvel's Agents of S.H.I.E.L.D. as an organic and appropriate extension of the MCU? Marvel's natural eagerness to associate the series with the sumptuous success of The Avengers provides one part of the answer, as trailers announce the new offering as being 'from Joss Whedon, the Director of Marvel's The Avengers' and a continuation of 'the saga that began in Marvel's The Avengers' (Marvel Entertainment, 2013b). The direct connection serves as further reassurance to the audience regarding what is essentially another risky experiment on Marvel's end, the textbook function of a brand: a guarantee of established quality. Whedon has already managed the unprecedented in delivering The Avengers, and he can presumably be relied upon to do so again. His authorship stands as a reassurance of viability for this form of transmedia expansion on a different scale from all previous endeavours, which followed better established practices of transmedia storytelling. Through his presence and the centrality of his authorship Marvel is not merely selling the MCU as a transmedia brand. They are selling a new kind of transmedia storytelling as part of the MCU brand.

\section{Strategies of Author-based Branding}

Yet it is not only the actual use of Whedon's name and his prominence in promotional materials that work to establish Agents of S.H.I.E.L.D. well within the MCU brand. It is also important to note the main themes that arise from the promotion of the series, and how those themes represent a use of the author brand to integrate the series into the greater universe. It is likewise interesting to see how themes are used to establish the show as distinct among television series in the same wellestablished genre, and to employ its transmedia connections to the cinematic universe as a selling point. We can find evidence of this tactic in comparing the thrust of the promotion of Agents of S.H.I.E.L.D. to that of The Avengers, and the roots of both the film and the series in Whedon's 
author brand. Three things are emphasized in marketing the series that align it with Whedon's body of work in general and with The Avengers specifically: characterization and teamwork, a particular style of humour, and an emphasis on fandom and a 'geeky', pop-cultural sensibility.

Going back to the supernatural bildungsroman Buffy the Vampire Slayer (Mutant Enemy Productions/Sandollar Television/Kuzui Entertainment/20 ${ }^{\text {th }}$ Century Fox Television, 1997-2003), Whedon's work has been known for its mix of the soap operatic and the fantastical, featuring sizeable ensemble casts and focusing on the relationships between them. His interest as he describes it is in stories about 'lost', 'broken and strange' people who are empowered by coming together and forming a family, from the outcast adolescents of Buffy to the hated mutants of the comic series Astonishing X-Men (Marvel Comics, 2004- ) (Itzkoff 2012b). This speciality of Whedon's was highlighted throughout the promotion of The Avengers as the key to the film's ability to juggle its unusually large cast, unprecedented in the superhero film genre, and to feature a dimension of depth and seriousness beyond its summer blockbuster status. As Feige reassured Variety, 'looking at Joss's body of work and the scripts that he's written and the TV shows, the characters never ever get lost' (Richardson 2012). The loneliness and strangeness of its heroes are themes that repeat in the film's marketing campaign and its promotional paratexts. Trailers and ads focus on the sometimes physical (and naturally explosive) conflict between teammates, with Bruce Banner/the Hulk quipping 'we're not a team, we're a time bomb', and villain Loki calling the Avengers 'lost creatures'.

The promotion of Agents of S.H.I.E.L.D. mirrors this thematic focus, starting from the trailer tagline, 'If they stand together we stand a chance'. The dubious nature of the team put together in the series, the various dysfunctions of its members and potential for conflict between them, are highlighted throughout the ads, character spotlights and features, painting them as another example of the 'band of misfits', in actress Ming-Na Wen's words, which has been ubiquitous in Whedon's body of work (McIntyre 2013). Putting the focus on the characters allows Whedon to speak of the 'intimacy' of the series as something typical to the MCU (Marvel Entertainment 2013e). This is a particularly useful claim to make, considering the difficulties of moving the universe from a 220 million dollar film to a weekly television show with a much smaller budget. The show acquires its license to proceed without cinematic spectacle by placing at the core of the MCU its use of characters and character-driven storytelling of a particular sort. The author figure acts here as a lens through which attention is focused on those particular qualities of the brand, which transcend the affordances of particular media and bridge gaps between the cinematic and the televised to render them part of a greater whole. Though Agents of S.H.I.E.L.D. cannot offer what The Avengers offered in terms of visual action and cinematic spectacle, it can be promoted as offering the same brand qualities of a focus on characters and teamwork.

The use of humour is another strategy for linking the two media through Whedon's creative signature. Mixed in with the action beats, trailers and ads for Agents of S.H.I.E.L.D. feature an irreverent and self-aware comedic style, delivered in one-liners that often break an otherwise serious or dramatic moment. From the very first lines of dialogue in the trailer, when a superior officer asks the character of Agent Ward (Brett Dalton) what 'Strategic Homeland Intervention, Enforcement and Logistics Division' means to him, he quips in response that 'it means that someone really wanted our initials to spell out S.H.I.E.L.D.'. This style of humour, wry, selfreferential and highly quotable, has long been associated with Whedon's work, and has, as mentioned, been cited as a particular way in which The Avengers has benefited from his 
screenwriting. Overall, the films of the MCU have taken a lighter approach to the superhero genre compared to those of their competitor, DC/Warner Bros., of the Dark Knight trilogy and Man of Steel. The franchise's flagship character, Robert Downey Jr.'s Iron Man, was particularly distinguished by his style of fast-talking one-liner humour, which meshed excellently with Whedon's own writing. The trailers for The Avengers repeatedly showcased this in the typically drama-breaking exchange between Iron Man and Captain America:

Captain America: 'Big man in a suit of armour... take that away, what are you?

Iron Man: ‘A genius billionaire playboy philanthropist.

In Agents of S.H.I.E.L.D., Downey is naturally absent; the show is limited in the star power it can draw on, much as it is limited in its budget and ability to deliver spectacle. Agent Ward's quote opening the trailer, along with other moments such as rogue hacker Skye's (Chloe Bennet) nonchalant 'Hey... what up?' to the agents barging in on her mid-dramatic speech, indicate to the audience that the MCU's distinct humour may nonetheless be found in the series, thanks to Whedon's creative signature. If the characterization and teamwork focus serve as a thematic commonality across media gaps, such stylistic resemblance serves to 'flavour' the MCU uniformly and to establish another reliable quality independent of the medium and form. To then attach those qualities to the name of a particular creative figure in the person of the writer-director is to turn them into an auteurist signature. That Whedon writes for Agents of S.H.I.E.L.D. not only as he has written for The Avengers, but as he has famously written throughout his career, infuses the brand extension with the aura of a passion project and stands as testimony of it being the result of a genuine creative drive.

The third feature at play refers less to a stylistic element and more to the use of the author figure in inspiring brand loyalty, as a figure for fandom to rally around following the medium transition. This mainly revolved around foregrounding Whedon in those spaces where fans and producers are physically or virtually closest: at conventions such as San Diego Comic Con (SDCC), and on social media sites such as Twitter. During the live-tweeting of the SDCC Agents of S.H.I.E.L.D. panel, Whedon's appearance on stage was covered with a Tweet reading simply 'Joss', without as much as closing punctuation (AgentsofSHIELD 2013). The audience's familiarity with Whedon is taken for granted. It is not mere familiarity, either, but a closeness implied by the use of the first name, constructing a personal connection between creator and fans. Of course, Marvel is relying here on Whedon's own famously passionate fandom, beyond the MCU connection, yet it is thus that the creator becomes a totem of sorts for the brand. Whedon's fan-friendliness is the same quality that Marvel attempts to foster when the cast promise in interviews that fans are 'going to love this' (Marvel Entertainment 2013c) and are 'gonna have so much fun watching' (Marvel Entertainment 2013d). As with any transmedia extension, it is those fans that Marvel is relying on to make up the core audience of Agents of S.H.I.E.L.D. whom Whedon serves for Marvel as an icon of powerful fandom.

The highlighting of thematic and stylistic elements that are bound in with another, pre-established creative identity outside of the MCU brand itself, suggests that another issue is at play here: a challenge unique to the Marvel transmedia strategy, originating in the fact that the MCU does not stand alone. For the most part, the characters, settings, fictional characters and creatures, artefacts and technologies that populate the storyworld have all been used, and continue to be used, in a 
variety of other media adaptations. Alongside the MCU, Marvel is currently running two main comics continuities - the original Marvel universe and the Ultimate Marvel universe - as well as the 'Marvel Animated Universe' shared by a number of animated television adaptations aimed at a younger audience, such as Hulk and the Agents of S.M.A.S.H and Avengers Assemble. Between the numerous versions of each character, location and event, Marvel thus ended up with the need to distinguish as well as unify, and to clearly delineate the borders of each of its many worlds. This is Whedon's second major function as creator: the establishment of a particular tone for the MCU, a consistency that would emphasize attention, careful thought and intent behind each extension as it was added, proof that Marvel are not opportunistic media landgrabbers, but inspired architects.

\section{Not Just an Easter Egg Farm: Whedon and the Marvel Transmedia Universe}

Joss Whedon's powerful presence in the promotion for Agents of S.H.I.E.L.D. conceals the fact that, as it happens, his actual involvement with the series week to week is fairly minimal. After being involved in creating the show and writing and directing the pilot episode, he then stepped back in favour of a different creative team. Acting as showrunners in his stead are Whedon's younger brother, Jed Whedon, and Jed's wife Maurissa Tancharoen. The younger Whedon and Tancharoen had both previously collaborated on a number of Joss Whedon productions: Dollhouse (20th Century Fox Television/Boston Diva Productions, 2009-10), internet original Doctor Horrible's Sing-Along Blog (Mutant Enemy Productions, 2008) and Whedon's adaptation of Much Ado about Nothing (Bellwether Pictures, 2012). Two additional executive producers and writers on the show are the aforementioned Jeph Loeb as Marvel Studios' Head of Television, and Jeffrey Bell - yet another former collaborator of Whedon's from Angel (Mutant Enemy/Greenwolf/Kuzui Enterprises/Sandollar Television/20th Century Fox Television, 1999-2004). Promotion of the series was not particularly eager to dwell on this point, with Jed Whedon, Tancharoen and Bell only making the occasional appearance in press. The practice of having a famous auteur involved in the early stages of a television series' creation, or directing a pilot to associate their name with the series, is not an unknown one - recall the hype surrounding Martin Scorcese directing the pilot of Boardwalk Empire. Yet Whedon's presence permeates Agents of S.H.I.E.L.D. uniquely even beyond the initial promotion, framing not merely the single episode as a television event, but the show as a whole. As further episodes of Agents of S.H.I.E.L.D. air, its official Twitter account continues to mainly feature witticisms from its scripts, thus maintaining the identity of the show: playful, quotable, character and dialogue driven: in a word, Whedonesque - another example of how the characterization of the show was not a one-time thing, a justification for its existence as a brand extension, but ongoing and continuously important.

A look through the continuing extension of the MCU into new media forms shows an intriguing pattern. Another frequent collaborator of Whedon's, Drew Goddard, was recently brought on by Marvel to create an MCU series on Netflix based on the character of Daredevil (Marvel.com 2013). Marvel is also now in negotiations with $\mathrm{ABC}$ for the creation of yet another televised extension recently confirmed as being helmed by Tara Butters and Michele Fazekas, both Dollhouse alumni (Zalben 2014). Simply put, the company is placing Whedon collaborators in every one of its media extensions, with the man himself leading the hub of the transmedia universe that is The Avengers. Beyond the presumed advantage of pre-established good working relations between different creators on the same storyworld, this strategy continues to signal to audiences and industry colleagues alike the importance of a unified authorial voice for the MCU. 
Before the airing of the Agents of S.H.I.E.L.D. pilot, as the series was taking shape, Whedon was presented with the question of how much ongoing connection there would be between the show and the other MCU films (Marechal 2013). The question touches directly on the nature of the series as a transmedia product, charting its specific contours and limitations, and is thus a question to be answered carefully. With its roots in the comics industry, Marvel would be more aware than most media producers of the problems of creating content that cannot be understood and enjoyed without considerable knowledge of the storyworld. Exactly this problem of decades of continuity, often spread across different titles, plagues the comics market today as it presents an often impassable hurdle to new readers. This balance of connection and independence is one that Agents of S.H.I.E.L.D., too, had to navigate, and the fact that this question is directed at Whedon suggests a considerable degree of power invested in him to do so. Whedon's answer assured that the show will not 'just be an Easter egg farm' (ibid.) but strive to rely on its own characters, bringing in the issue of authenticity in force as he guarantees the ability of Agents of S.H.I.E.L.D. to stand on its own merits, while also showing that it has no need of such tactics. It is an established MCU product and is tied in to the brand by other merits - his own seal of approval and ability to deliver. This practice, a kind of creative feudalism with a central leader surrounded by semi-independent vassal showrunners, is as unprecedented as the concept of the MCU itself. It is distinctly different from the models that either Jenkins or Evans describe, and invites reconsideration of how transmedia storyworlds are made.

In an ironic twist, as the ratings of Marvel's Agents of S.H.I.E.L.D. floundered following the first two episodes, rumours surfaced in the press that Whedon had been called in to do last-minute page one re-writes to forthcoming scripts (Shah 2013). This shows the potential danger of Marvel's strategy of attaching a major creator to their brand: namely, that the creator's own brand would come to overshadow that which it is supposed to authenticate. When the Wachowskis called on famous names to add to the Matrix franchise, the strategy was one of enrichment, not attachment. Shinichiro Watanabe and Neil Gaiman created stories within the Matrix universe and guaranteed the merit of these stories by their presence, but they did not themselves shape that universe and its themes and tone. They brought their creative signatures into an established framework. Conversely, as Marvel have integrated Whedon's creative signature as part and parcel of the framework of the MCU, they now face a new risk to the authenticity of their brand extensions. Time must tell which authorship will win out, the institutional or the individual, or whether the two can in fact function in harmony to carry the brand further across the transmedia landscape.

\section{References}

ABC (2013) 'Get the Scoop: Marvel's Agents of S.H.I.E.L.D.', ABC.go.com, 11 May. Accessible at http://abc.go.com/shows/marvels-agents-of-shield/news/briefingroom/20130510-marvels-agentsof-shield-get-the-scoop. Accessed December 232013.

AgentsofSHIELD (2013) 'Joss' [Tweet], 19 July. Accessible at https://twitter.com/AgentsofSHIELD/status/358329487190003712. Accessed 23 March 2014.

Dove, S. (2013) 'Marvel's Agents of S.H.I.E.L.D. on the Cover of Entertainment Weekly', ABC.go.com, August 21. Accessible at http://abc.go.com/shows/marvels-agents-ofshield/news/briefing-room/08212013-marvels-agents-of-shield-on-the-cover-of-entertainmentweekly. Accessed 23 December 232013. 
Evans, E. (2011) Transmedia Television: Audiences, New Media and Daily Life, London: Routledge

Itzkoff, D. (2012a) 'Joss Whedon Creating "S.H.I.E.L.D." Pilot for ABC', New York Times, Arts Beat, [blog], 29 August. Accessible at http://artsbeat.blogs.nytimes.com/2012/08/29/joss-whedoncreating-s-h-i-e-l-d-pilot-for-abc/? php=true\& type=blogs\& r $=0$. Accessed 25 March 2014

Itzkoff, D. (2012b) 'A Film's Superheroes Include the Director', New York Times, Arts Beat, [blog], 15 April. Accessible at http://www.nytimes.com/2012/04/15/movies/joss-whedon-directs-theavengers.html. Accessed 25 March 2014

Jenkins, H. (2006) Convergence Culture: Where Old and New Media Collide, New York: New York University Press

--- (2007) 'Transmedia Storytelling 101', Confessions of an Aca-Fan, [blog], 22 March. Accessible at http://henryjenkins.org/2007/03/transmedia storytelling 101.html. Accessed 28 March 2014

Levine, M. (2003) A Branded World: Adventures in Public Relations and the Creation of Superbrands, New Jersey: John Wiley \& Sons

Lury, C. (2004) Brands: The Logos of the Global Economy, London: Routledge

Marechal, A. J. (2013) 'TCA: Producers Hope Agents of SHIELD’s Secrecy Brings Back

"Urgency" to TV', Variety, 4 August. Accessible at http://variety.com/2013/tv/news/marvel-agentsof-shield-abc-joss-whedon-1200573920/. Accessed 25 March 2014

Marvel.com (2013) 'Drew Goddard Joins Daredevil on Netflix', Marvel.com, 6 December.

Accessible at

http://marvel.com/news/tv/2013/12/6/21604/drew_goddard_joins_daredevil_on_netflix. Accessed

23 March 2014

Marvel Entertainment (2013a) 'Marvel's Agents of S.H.I.E.L.D. - Promo 1', [video file], 12 May. Accessible at http://www.youtube.com/watch?v=ySsw6aetys\&list=SPK5HARgNfgj9cUwtYprubFfFzZGW5OIN $\mathrm{k} \&$ index $=25$. Accessed 23 March 2014

Marvel Entertainment (2013b) 'Marvel's Agents of S.H.I.E.L.D. - Trailer 1 (Official)', [Video file], 13 May. Accessible at http://www.youtube.com/watch?v=T3T-evQZiQo. Accessed 23 March 2014

Marvel Entertainment (2013c) 'Marvel's Agents of S.H.I.E.L.D. - Level 7 Access With Agent Ward', [video file], 10 July. Accessible at

https://www.youtube.com/watch?feature=player_embedded\&v=AYZ_zf2Z54Q. Accessed 23 March 2014

Marvel Entertainment (2013d) 'Marvel's Agents of S.H.I.E.L.D. - Level 7 Access with Skye', [video file], 7 August. Accessible at

https://www.youtube.com/watch?feature=player embedded $\& v=8$ CxotaKxXZ4. Accessed 23 March 2014

Marvel Entertainment. (2013e) 'Marvel's Agents of S.H.I.E.L.D. - Featurette 1', [video file], 11 September. Accessible at http://www.youtube.com/watch?v=gjLUQ72lynY\&list=SPK5HARgNfgj9cUwtYprubFfFzZGW5O $1 \mathrm{Nk} \&$ index $=15$. Accessed 23 March 2014

McIntyre, G. (2013) ““Agents of S.H.I.E.L.D.” Star Ming-Na Wen on Joss Whedon's Quiet Energy', Los Angeles Times, Hero Complex, 1 October. Accessible at http://herocomplex.latimes.com/tv/agents-of-s-h-i-e-l-d-star-ming-na-wen-on-joss-whedons-quiet- 
energy/\#/0. Accessed 25 March 2014

Polo, S. (2013) 'Joss Whedon Practically Parachuted in to Help Thor Writers, Like a Screenwriting Ninja', The Mary Sue, 18 September. Accessible at http://www.themarysue.com/joss-whedon-thorscript/. Accessed 25 March 2014

Richardson, A. (2012). 'Full Shadow \& Act Report from Marvel Studios' "The Avengers" Press Junket', Indiewire, Shadow and Act, [blog], 18 April. Accessible at http://blogs.indiewire.com/shadowandact/full-shadow-and-act-report-from-marvel-studios-theavengers-press-junket. Accessed 25 March 2014

Shah, B. (2013), 'Joss Whedon is Last-minute Rewriting S.H.I.E.L.D. and Other TV Gossip', Defamer, [blog], 9 October. Accessible at http://defamer.gawker.com/joss-whedon-is-last-minuterewriting- $\quad$ s-h-i-e-l-d-and-o-1284376623. Accessed 25 March 2014

Tenderich, B. (2013) Design Elements of Transmedia Branding, [e-book], Annenberg, CA: USC Annenberg Innovation Lab. Accessible at http:/www.annenberglab.com/sites/default/files/uploads/Design\%20Elements\%20of\%20Transmedi a\%20Branding.pdf. Accessed 23 March 2014

Wigler, J. (2012) “"Avengers” and Beyond: Why Joss Whedon's Marvel Deal is Great News', MTV News, 8 August. Accessible at http://www.mtv.com/news/articles/1691426/avengers-whedonmarvel-deal.jhtml. Accessed 25 March 2014

Zalben. A. (2014) 'Marvel's “Agent Carter” Gets a Whedon-approved Writing Team', MTV News, 17 January. Accessible at http://www.mtv.com/news/articles/1720670/agent-carter-whedonwriters.jhtml. Accessed 25 March 2014 